\title{
Vertragsänderung statt effektiver Unterwanderung
}

verfassungsblog.de/vertragsnderung-statt-effektiver-unterwanderung/

Frank Schorkopf Mi 14 Dez 2011

Mi 14 Dez

2011

Ist nicht jeder Rechtssatz, jedes Gesetz, ist nicht jeder Vertrag eine lex imperfecta? In einem organisierten politischen Gemeinwesen, wir nennen seine Hauptform Staat, beruht Recht auf Kompromissen. Eine freiheitliche Ordnung - und nur als solche ist politische Herrschaft für uns heute hinnehmbar - schöpft das Recht aus einer Mehrheitsentscheidung. Selbst der Verfassung müssen regelmäßig nicht alle Bürger zustimmen, damit sie in Kraft treten kann und dennoch werden alle weiteren Entscheidungen für Jedermann in ihrem Geltungsbereich verbindlich.

Nun sind die Mitgliedstaaten der Europäischen Union nicht ihre Bürger. Sie sind Staaten und sie bestehen weiter auf der klassischen Regel, sich nicht ohne ihre Zustimmung von einem völkerrechtlichen Vertag binden zu lassen. Dadurch wird der Zwang zum Kompromiss erhöht, wenn die Staaten solche Verträge - wie den EU- und den AEU-Vertrag - aushandeln. Dadurch wird es wahrscheinlicher, dass eine tatsächlich vereinbarte Norm von ihrer idealen Gestalt, im Sinne einer "Idee von der Norm" abweicht. Aber wer vermag schon zu sagen, wie die ideale Norm aussehen sollte?

Dem europäischen Defizitverfahren für die Wirtschafts- und Währungsunion (Art. 126 AEUV) werden mit Blick auf die europäische Staatsschuldenkrise Defizite bescheinigt. In diesen Tagen treten die Änderungen zu diesem Verfahren in Kraft, die Rat und Europäisches Parlament der EU-27 mühevoll ausgehandelt haben. Könnte es aber nicht auch sein, dass die Normen des Defizitverfahrens gar nicht so ineffektiv waren, sondern der Wille zu ihrer Anwendung defizitär war? Das Defizitverfahren kannte und kennt Tatbestand und Rechtsfolge. Wenn dem so ist, dann wird es für jeden Rechtsetzer in einer Rechtsgemeinschaft schwierig, eine normative Architektur zu entwerfen, die den Willen der Handelnden zwingt. Das bislang einzige Verfahren vor dem Europäischen Gerichtshof zu dieser Problematik macht das sehr anschaulich: Deutschland und Frankreich hatten, zusammen mit den anderen Mitgliedstaaten, nicht den Willen, den vorgesehenen, nächsten Verfahrensschritt zu beschließen. Sie wichen aus und ersannen eine nicht vorgesehene Rechtsfolge. Der Gerichtshof sah in diesem „Ausbruch“ aus dem Verfahrensrahmen einen Verstoß gegen das europäische Recht (Rs. C-27/04).

Sicherlich kann geltendes Recht stets effektiver ausgestaltet werden. Nettesheim hat Recht, wenn er schreibt, dass 26 Mitgliedstaaten der Europäischen Union ein Parallelverfahren zum bestehenden Defizitverfahren einrichten könnten, mit dem sie sich untereinander verschärften Sanktionen unterwerfen. Soweit das Unionsrecht einen solchen nationalen Handlungsfreiraum bestehen lässt, können die Mitgliedstaaten diesen durch völkerrechtliche Bindungen weiter einschränken. Deutschland, Frankreich und die Benelux-Staaten konnten 1985 das Schengener Abkommen als völkerrechtlichen Vertrag abschließen, weil die Grenzkontrolle von Personen in das supranationale Recht der damaligen Europäischen Wirtschaftsgemeinschaft nicht einbezogen war. Es lohnt sich, dieses Dossier in Erinnerung zu rufen, weil dieser Tage das Bundesfinanzministerium „Schengen“ als rechtfertigendes Vorbild für den geplanten fiscal compact in Anspruch nimmt. Die politischen Motive für einen solchen Schritt können unterschiedlich sein: der Wille zur vertieften Integration oder der Wunsch nach effektiveren Regeln - Motive interessieren den Juristen an dieser Stelle aber nicht.

Das Problem der Gipfelbeschlüsse vom 9. Dezember ist ein anderes. Mit der geplanten zweiten Option eines intergouvernementalen Defizitverfahrens wird es keinen Mitgliedstaat mehr geben, auf den das derzeitig geltende Defizitverfahren in der Praxis noch anwendbar sein wird. Großbritannien hat den Euro einstweilen nicht eingeführt und hat sich zudem Ausnahmen für diesen Schritt ausbedungen. Mit dem Parallelvertrag werden also zwei, im Ergebnis problematische Wege vorgezeichnet: Auf dem ersten Weg müssten die 26 Mitgliedstaaten damit rechnen, das Großbritannien nicht damit einverstanden ist, dass die Organe der EU für das neue Verfahren tätig werden. In diesem Fall müssten die Mitgliedstaaten einen anderen Dienstleister finden, der die administrativen Aufgaben der Kommission im Defizitverfahren kompetent übernähme. Wer sollte das sein? Der Internationale Währungsfonds, das Generalsekretariat des Europäischen Stabilitätsmechanismus (ESM), oder 
nicht doch die bereits zuständige Generaldirektion der Kommission, dann unter einem anderen Namen? Der zweite Weg, bei dem die echte Kommission zur Verfügung stünde, würde im Ergebnis zu einer faktischen Änderung des AEU-Vertrages führen. Denn es gäbe für das derzeitige Verfahren in der Praxis keine Anwendungsfälle mehr. Der Normtext des Art. 126 AEUV würde durch die neue Praxis des zweitoptionalen Defizitverfahrens überlagert.

Die faktische Vertragsänderung ist aber ein Instrument, das zumindest im Recht der Europäischen Union jeden aufhorchen lassen sollte. Das Primärrecht enthält seit seiner letzten Änderung durch den Vertrag von Lissabon eine ausführliche Systematik der Änderungsverfahren. Sie garantieren jedem Mitgliedstaat, jedem Bürger und auch „den Märkten“ einen formellen Willensbildungsprozess, nach dem die Verträge geändert werden können. Diese Verfahren - und ihre ausschließliche Anwendung - sind die roten Siegel der europäischen

Rechtsgemeinschaft. Sie garantieren überhaupt erst die Normativität des europäischen Rechts - auch wenn es als imperfekt empfunden wird. Sie sind die Grundnorm für das Vertrauen.

Frank Schorkopf lehrt Öffentliches Recht an der Georg-August-Universität Göttingen.

\section{LICENSED UNDER CC BY NC ND}

SUGGESTED CITATION Schorkopf, Frank: Vertragsänderung statt effektiver Unterwanderung, VerfBlog, 2011/12/14, http://verfassungsblog.de/vertragsnderung-statt-effektiver-unterwanderung/. 